\title{
Identification of the divergent calmodulin-binding motif in yeast Ssb1/Hsp75 protein and in other HSP70 family members
}

R.C. Heinen,

L. Diniz-Mendes, J.T. Silva and V.M.F. Paschoalin
Departamento de Bioquímica, Instituto de Química, Universidade Federal do Rio de Janeiro, Rio de Janeiro, RJ, Brasil

\section{Correspondence \\ V.M.F. Paschoalin \\ Departamento de Bioquímica \\ Instituto de Química \\ UFRJ, CT, Bloco A, Sala 545 \\ 21949-900 Rio de Janeiro, RJ \\ Brasil \\ Fax: +55-21-2562-7266 \\ E-mail: paschv@iq.ufrj.br \\ Research supported by FAPERJ, CAPES, CNPq, and FUJB (Fundação Universitária José Bonifácio).}

Received July 29, 2005 Accepted June 14, 2006

\begin{abstract}
Yeast soluble proteins were fractionated by calmodulin-agarose affinity chromatography and the $\mathrm{Ca}^{2+} /$ calmodulin-binding proteins were analyzed by SDS-PAGE. One prominent protein of $66 \mathrm{kDa}$ was excised from the gel, digested with trypsin and the masses of the resultant fragments were determined by MALDI/MS. Twenty-one of 38 monoisotopic peptide masses obtained after tryptic digestion were matched to the heat shock protein Ssb1/Hsp75, covering 37\% of its sequence. Computational analysis of the primary structure of Ssb1/ Hsp75 identified a unique potential amphipathic $\alpha$-helix in its $\mathrm{N}$ terminal ATPase domain with features of target regions for $\mathrm{Ca}^{2+}$ calmodulin binding. This region, which shares $89 \%$ similarity to the experimentally determined calmodulin-binding domain from mouse, Hsc70, is conserved in near half of the 113 members of the HSP70 family investigated, from yeast to plant and animals. Based on the sequence of this region, phylogenetic analysis grouped the HSP70s in three distinct branches. Two of them comprise the non-calmodulin binding Hsp70s BIP/GR78, a subfamily of eukaryotic HSP70 localized in the endoplasmic reticulum, and DnaK, a subfamily of prokaryotic HSP70. A third heterogeneous group is formed by eukaryotic cytosolic HSP70s containing the new calmodulin-binding motif and other cytosolic HSP70s whose sequences do not conform to those conserved motif, indicating that not all eukaryotic cytosolic Hsp70s are target for calmodulin regulation. Furthermore, the calmodulinbinding domain found in eukaryotic HSP70s is also the target for binding of Bag-1 - an enhancer of ADP/ATP exchange activity of Hsp70s. A model in which calmodulin displaces Bag-1 and modulates Ssb1/Hsp75 chaperone activity is discussed.
\end{abstract}

\section{Introduction}

Calcium ions, present inside all eukaryotic cells, are important second messengers in the transduction of biological signals. In budding yeast, transient increases in $\mathrm{Ca}^{2+}$
Key words

- Ssb1/Hsp75

- $\mathrm{Ca}^{2+} /$ calmodulin complex

- $\mathrm{Hsc70}$

- Calmodulin-affinity peptide

- Bag1

- Saccharomyces cerevisiae 
The information encoded in the transient increase in $\mathrm{Ca}^{2+}$ concentration is transduced by intracellular $\mathrm{Ca}^{2+}$-binding proteins, which convert the $\mathrm{Ca}^{2+}$ signal to a wide variety of biochemical changes. The best studied $\mathrm{Ca}^{2+}$ sensor is calmodulin, a small ubiquitous acidic protein member of the E-F hand $\mathrm{Ca}^{2+}$ binding protein family. Upon sequestering $\mathrm{Ca}^{2+}$, calmodulin changes its conformation and reveals two methionine-rich hydrophobic patches that specifically interact with calmodulin-binding domains in a variety of proteins (2), regulating their activities.

$\mathrm{Ca}^{2+} /$ calmodulin-binding domains are segments of approximately 20 amino acids often having a net positive charge, moderate hydrophilicity and moderate to high helical hydrophobic moment, which form basic amphipathic $\alpha$-helices with hydrophobic and basic residues segregated to opposite sides (3). Rhoads and Friedberg (4) found three classes of calmodulin-binding motifs. A program using algorithms based on these motifs is available in the Calmodulin Target Database (calcium.oci.utoronto.ca/) but it works by analyzing one sequence at a time, which prevents a global analysis of an entire genome. In addition, the existence of posttranslational modifications is not considered in the analysis of genomic derivative sequences and can generate false-positive results. Moreover, divergent calmodulin-binding motifs cannot be detected using this approach. Sequence searches based on these criteria are not sufficient to identify unequivocally calmodulin target proteins and different analytical techniques, including calmodulin affinity chromatography and the gel overlay assay using labeled calmodulin, should be used in order to identify new activities and processes which are targets for $\mathrm{Ca}^{2+} /$ calmodulin and to confirm potential candidates identified by proteomic tools.

Characterized calmodulin-binding proteins in yeast include $\mathrm{Cmk} 1 \mathrm{p}$ and $\mathrm{Cmk} 2 \mathrm{p}$, members of the type II calcium/calmodulin-dependent serine/threonine protein kinases family (5);
Cmp2p, an isoform of the catalytic subunits of calcineurin (6); Dst1p, that acts in transcription elongation (7); Myo4p, a class $\mathrm{V}$ myosin heavy chain (8), and Arc35p, a component of the Arp2/3 actin-organizing complex (9). Proteome chip analysis (bioinfo.mbb.yale.edu/ proteinchip) using biotinylated calmodulin as a probe identified 33 additional peptides able to bind calmodulin (19 of them in a $\mathrm{Ca}^{2+}$ independent manner) (10). The number of putative calmodulin-binding proteins has been further extended by systematic identification of yeast protein complexes by mass spectrometry, which detected 21 new calmodulin targets (11), and by two-hybrid screening that added 2 additional components to the increasing list of these proteins (12). Despite the growing number of identified calmodulin-binding proteins, a complete panel has not been obtained.

In the present study, we report the identification of the yeast stress protein Ssb1/ Hsp75 as a new member of the calmodulinbinding protein family based on its ability to complex with calmodulin-agarose. The putative calmodulin-binding domain of Ssb1/ Hsp75 was identified on the basis of structural similarity to the experimentally determined calmodulin-binding domain of mouse Hsc70. The physiological significance of this association will be discussed.

\section{Material and Methods}

\section{Microorganisms, cell growth and preparation of cell-free extracts}

Saccharomyces cerevisiae strain 332-5A

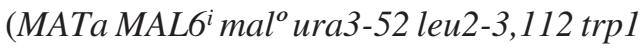
his), obtained from C. Michels (Queens College, New York, NY, USA), was used in the present study. Cells were grown in YEMsupplemented medium $(1.3 \%$ yeast extract, $2 \%$ maltose, plus $0.2 \%\left(\mathrm{NH}_{4}\right)_{2} \mathrm{SO}_{4}$ and $0.2 \%$ $\left.\mathrm{KH}_{2} \mathrm{PO}_{4}, \mathrm{pH} 5.2\right)$ at $28^{\circ} \mathrm{C}$ in a rotary shaker operated at $160 \mathrm{rpm}$. Growth was monitored by turbidity measurements at $570 \mathrm{~nm}$. A 
cell-free extract was prepared by shaking yeast cells ( $5 \mathrm{~g}$ dry weight) with $12 \mathrm{~g}$ glass beads $(0.45 \mathrm{~mm}$ in diameter) and $20 \mathrm{~mL} 20$ $\mathrm{mM}$ Tris- $\mathrm{HCl}$ buffer, $\mathrm{pH} 7.5$, plus $1 \mathrm{~mL}$ of the protease inhibitor cocktail (Sigma-Aldrich Co., St. Louis, MO, USA) containing 4-(2-aminoethyl)benzenesulfonyl fluoride, pepstatin A, E-64 and 1,10-phenantroline, in a Bead Beater homogenizer cooled with crushed ice. Cells were broken by alternating 6 cycles of homogenization ( $1 \mathrm{~min}$ each) and resting in an ice bath $(2 \mathrm{~min})$. After centrifugation at $12,000 \mathrm{~g}$ for $10 \mathrm{~min}$ at $4^{\circ} \mathrm{C}$, the supernatant was collected and centrifuged again at $105,000 \mathrm{~g}$ for $60 \mathrm{~min}$ at $4^{\circ} \mathrm{C}$.

\section{Isolation of calmodulin-binding proteins and} SDS-PAGE

Eight milliliters of the cell-free extract (350 mg protein) was applied to a calmodulinagarose affinity column (Sigma-Aldrich Co.; $10 \times 1.5 \mathrm{~cm}$ in diameter, flow rate of $20 \mathrm{~mL} / \mathrm{h}$ ), equilibrated with buffer A (20 mM Tris-HCl buffer, $\mathrm{pH} 7.5$, containing a protease inhibitor cocktail (Sigma-Aldrich Co.; 3 mM MgCl 2,1 mM EGTA, $100 \mathrm{mM} \mathrm{NaCl}$, and $2 \mathrm{mM} \mathrm{CaCl}_{2}$ ) at $4^{\circ} \mathrm{C}$. Following application of the sample, the flow was stopped and the proteins were left to interact with the column for $18 \mathrm{~h}$. After washing unbound proteins with 20 column volumes of buffer $\mathrm{A}, \mathrm{Ca}^{2+} /$ calmodulin-binding proteins were eluted with buffer $\mathrm{A}$ containing $2 \mathrm{mM}$ EGTA in place of $2 \mathrm{mM} \mathrm{CaCl}_{2}$. Fractions of $1 \mathrm{~mL}$ were collected and the protein content of the different fractions was assayed by the bicinchoninic acid method (13) using bovine serum albumin as standard. Fractions with the highest protein content were pooled and concentrated/desalted by centrifugation using Centricon-10 ultra-filtration membranes with a pore cut-off of $10 \mathrm{kDa}$ (Amicon Inc., Danvers, MA, USA). The concentrated pool of $\mathrm{Ca}^{2+} /$ calmodulin-binding proteins was fractionated on $10 \%$ SDS-PAGE by the method of Laemmli (14). Gels were stained with Coomassie blue G250.

\section{Matrix-assisted laser desorption/ionization mass spectrometry analysis}

Coomassie blue-stained bands containing 40-100 pmol of protein were excised from the gel and transferred to nylon membranes. Proteins on the membranes were digested with trypsin and the masses of the resulting peptides were determined by matrix-assisted laser desorption/ionization mass spectrometry (MALDI/MS) at the Biotechnology Resource Laboratory (W.H. Keck Foundation, Yale University, Yale, CT, USA). One hundred femtomoles bradykinin $\left(\mathrm{MH}^{+}=1060.57\right)$ and ACTH clip $\left(\mathrm{MH}^{+}=2466.702\right)$ were applied as an internal calibrant. The masses obtained were used to search protein databases for matches using the ProFound software (prowl.rockefeller. edu) with peptide mass accuracy set at $0.5 \mathrm{Da}$.

\section{Results}

\section{Isolation and identification of a 66-kDa peptide as Ssb1/Hsp75}

We have previously reported the presence of a large number of calmodulin-binding proteins in yeast (15). To identify some of these proteins, cell-free extracts were prepared from cells harvested at the exponential phase of growth in maltose $\left(\mathrm{OD}_{570 \mathrm{~nm}}=0.8\right)$ and fractionated by affinity chromatography in calmodulin-agarose. Eluted calmodulin-binding proteins were pooled, concentrated/desalted through Centricon-10 membranes and analyzed by SDS-PAGE (Figure 1, lane I). In agreement with previous findings, Coomassie blue-stained gel showed approximately $40 \mathrm{cal}-$ modulin-binding proteins with molecular masses ranging from 17 to $86 \mathrm{kDa}$. Many of these polypeptides should contain a calmodulin-binding domain and interact directly with calmodulin since they have been reported to bind to a ${ }^{125} \mathrm{I}$-calmodulin probe in a gel overlay assay (15).

A large well-isolated polypeptide band 
Figure 1. SDS-PAGE analysis of the calmodulin-binding proteins from Saccharomyces cerevisiae. Total soluble proteins extracted from 332-5A cells harvested during growth in YEMAL medium were chromatographed on a calmodulin-agarose column. Eluted $\mathrm{Ca}^{2+} /$ calmodulin-binding proteins (lane I) were fractionated by $10 \%$ SDS-PAGE and stained with Coomassie blue. Molecular weight markers (lane P) were: myosin (205 kDa), B-galactosidase (116 kDa), phosphorylase b $(97.4 \mathrm{kDa})$, bovine serum albumin (66 kDa), ovalbumin (45 $\mathrm{kDa}$ ), and carbonic anhydrase (29 kDa). The arrow indicates the 66-kDa calmodulin-binding protein. with an apparent molecular mass of $66 \mathrm{kDa}$ (Figure 1, arrow) was chosen for identification. The band was excised from the gel, the protein was electrophoretically transferred to a nylon membrane and digested with trypsin and the masses from the resulting peptides were determined by MALDI-MS. Thirty-eight monoisotopic peptide masses were obtained that did not appear in the blank (Figure 2). Of these masses, 21 were

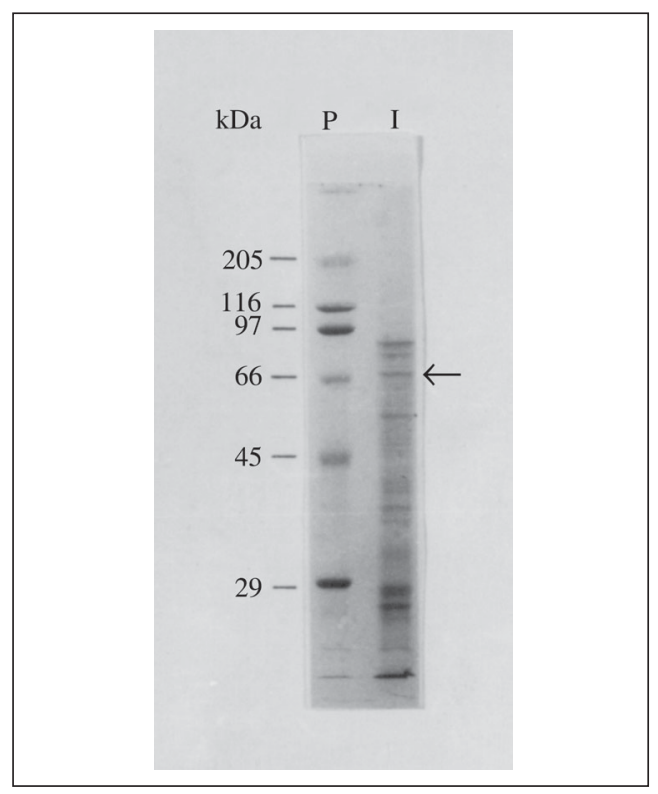

matched (using the ProFound program) (16) within $\mathrm{a} \pm 0.5 \mathrm{Da}$ error to predicted tryptic peptides expected from Ssb1/Hsp75, a member of the yeast HSP70 protein family (Table 1 and Figure 3). A second significant score (19 of the 38 peptide masses) was found for Ssb2/Hsp76 (Figure 3). Ssb1/Hsp75 displays $99.0 \%$ identity and $99.7 \%$ similarity to $\mathrm{Ssb} 2 /$ Hsp76 (17). However, Ssb1/Hsp75 differs from $\mathrm{Ssb} 2 / \mathrm{Hsp} 76$ by four amino acid substitutions (E48Q, M412T, C434V, and A435S). The E48Q, C434V and A435S substitutions, located inside the expected tryptic peptides 38-50 and 430-450, were sufficient to differentiate Ssb1 from Ssb2. The corresponding peptide masses of 1479.75 and $2477.05 \mathrm{Da}$ were matched to Ssb1, but were absent from Ssb2 (Figure 3). Thus, we unequivocally identified the 66-kDa polypeptide as Ssb1/ Hsp75, a previously undetected member of the putative set of calmodulin-binding proteins already identified in yeast (5-9).

Several functions have been attributed to the proteins of the HSP70 family, including uncoating of clathrin-coated vesicles (18), directional translocation of newly synthesized protein across subcellular membranes (19), as well as disruption of inappropriate protein-

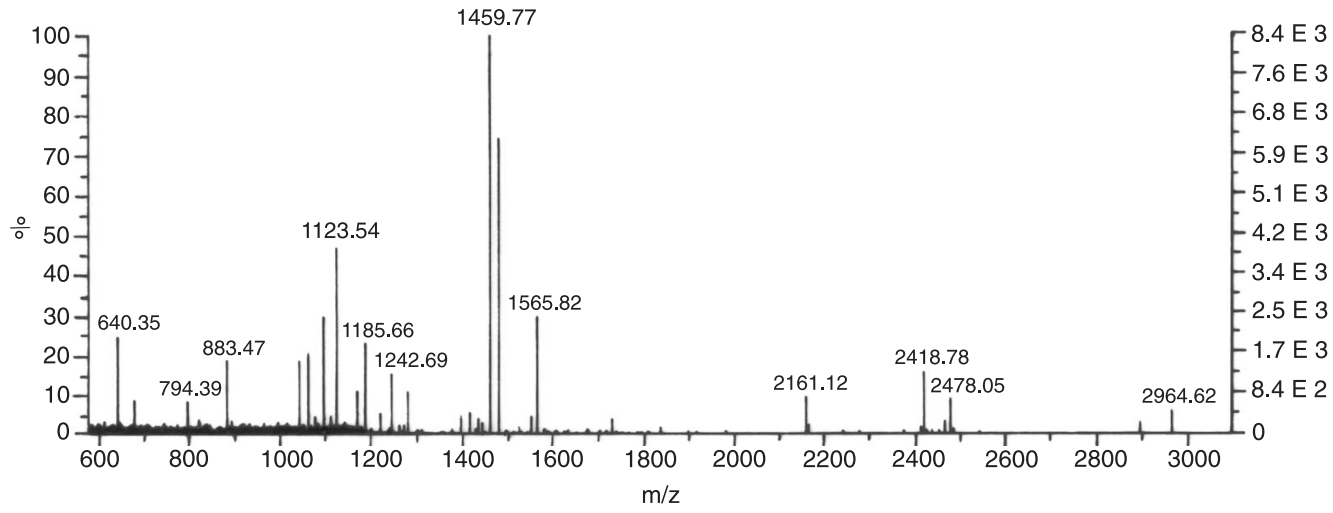

Figure 2. MALDI-MS spectrum of the tryptic digests of the $66-\mathrm{kDa}$ protein. The band containing the $66-\mathrm{kDa}$ protein was digested with trypsin and the resulting digest was analyzed by mass spectrometry. One hundred femtomoles of bradykinin and ACTH clip were used as internal calibrants for peptide mass. A total of 38 monoisotopic peaks with molecular masses of $640.35,678.34,794.39,822.39,883.47,1041.52,1095.52,1123.54,1167.6,1185.66$, 1218.64, 1242.69, 1260.68, 1270.63, 1278.66, 1377.74, 1.394.75, 1415.75, 1424.68, 1435.75, 1442.72, 1459.77, 1479.75, 1551.82, 1564.82, 1580.79, 1604.8, 1624.8, 1631.82, 1675.73, 1701.79, 1708.81, 1716.86, 1729.97, $1979.94,2160.13,2417.78$, and 2477.05 Da were obtained that did not appear in the blank control. 
Table 1. Peptides identified by mass spectrometry in a tryptic digest of the 66-kDa calmodulin-binding protein.

\begin{tabular}{rrrrll}
\hline $\begin{array}{r}\text { Measured } \\
\text { mass (Da) }\end{array}$ & $\begin{array}{r}\text { Computed } \\
\text { mass (Da) }\end{array}$ & Error & $\begin{array}{c}\text { Missed } \\
\text { cut }\end{array}$ & \multicolumn{1}{c}{ Peptide sequence } & $\begin{array}{r}\text { Residue } \\
\text { numbers }\end{array}$ \\
\hline 1479.751 & 1479.748 & 0.002 & 0 & VTPSFVAFTPEER & $38-50$ \\
883.471 & 883.475 & -0.003 & 0 & NQAALNPR & $58-65$ \\
794.391 & 794.405 & -0.013 & 0 & NTVFDAK & $66-72$ \\
1123.541 & 1123.538 & 0.003 & 1 & RFDDESVQK & $78-86$ \\
678.341 & 678.362 & -0.020 & 0 & TWPFK & $90-94$ \\
2160.131 & 2160.108 & 0.023 & 0 & VIDVDGNPVIEVQYLEETK & $95-113$ \\
1551.821 & 1551.809 & 0.011 & 0 & TFSPQEISAMVLTK & $114-127$ \\
1564.821 & 1564.812 & 0.008 & 0 & AVITVPAYFNDAQR & $143-156$ \\
1185.661 & 1185.659 & 0.001 & 0 & DAGAISGLNVLR & $161-172$ \\
1729.971 & 1729.949 & 0.022 & 0 & IINEPTAAAIAYGLGAGK & $173-190$ \\
1394.751 & 1394.743 & 0.007 & 1 & ARFEDLNAALFK & $302-313$ \\
1167.601 & 1167.605 & -0.003 & 0 & FEDLNAALFK & $304-313$ \\
1242.691 & 1242.695 & -0.003 & 0 & STLEPVEQVLK & $314-324$ \\
1459.771 & 1459.776 & -0.004 & 0 & SQIDEVVLVGGSTR & $331-344$ \\
1041.521 & 1041.526 & -0.004 & 0 & LLSDFFDGK & $351-359$ \\
2477.051 & 2477.141 & -0.089 & 0 & TFTTCADNQTTVQFPVYQGER & $430-450$ \\
1278.661 & 1278.658 & 0.002 & 0 & ENTLLGEFDLK & $455-465$ \\
1218.641 & 1218.644 & -0.003 & 0 & SSNITISNAVGR & $501-512$ \\
1095.521 & 1095.515 & 0.006 & 0 & MVNQAEEFK & $521-529$ \\
822.391 & 822.400 & -0.008 & 0 & AADEAFAK & $530-537$ \\
640.351 & 640.353 & -0.002 & 1 & KHEAR & $538-542$ \\
\hline & & & & &
\end{tabular}

A total of 38 monoisotropic molecular masses (see legend to Figure 2) were used to search for matches in the Saccharomyces cerevisiae protein database using the ProFound program at http://prowl.rockefeller.edu (16). Residue numbers refer to amino acid positions in yeast Hsp75/Ssb1 protein (Swiss-Prot accession number P11484). Peptide in italic type (430-TFTTCADNQTTVQFPVYQGER-450) contains a cys modified with acrylamide.

\footnotetext{
Ssb1/Hsp75

1 aegvfqgaig dlgttyscv atyessveii aneggnrVTP SFVAFTPEER LIGDAAKNQA 61 ALNPRNTVFD AKrligrRFD DESVQKdmkT WPFKVIDVDG NPVIEVQYLE ETKTFSPQEI 121 SAMVLTKmke iaeakigkkv ekAVITVPAY FNDAQRqatk DAGAISGLNV LRIINEPTAA 181 AIAYGLGAGK sekerhvlif dlgggtfdvs llhiaggvyt vkstsgnthl ggqdfdtnll 241 ehfkaefkkk tgldisddar alrrlrtaae rakrtlssvt qttvevdslf dgedfesslt 301 rARFEDLNAA LFKSTLEPVE QVLKdakisk SQIDEVVLVG GSTRipkvqk LLSDFFDGK

361 leksinpdea vaygaavqga iltgqstsde tkdlllldva plslgvgmag dmfgivvprn 421 ttvptikrrT FTTCADNQTT VQFPVYQGER vnckENTLLG EFDLKnipmm pagepvleai 481 fevdangilk vtavekstgk SSNITISNAV GRIsseeiek MVNQAEEFKA ADEAFAKKHE 541 ARqrlesyva sieqtvtdpv lssklkrgsk skieaalsda laalqiedps adelrkaevg 601 lkrvvtkams sr

\section{Ssb2/Hsp76}

1 aegvfqgaig idlgttyscv atyessveii aneqgnrvtp sfvaftpqer LIGDAAKNQA 61 ALNPRNTVFD AKrligrRFD DESVQKdmkT WPFKVIDVDG NPVIEVQYLE ETKTFSPQEI 121 SAMVLTKmke iaeakigkkv ekAVITVPAY FNDAQRqatk DAGAISGLNV LRIINEPTAA

181 AIAYGLGAGK sekerhvlif dlgggtfdvs lihiaggvyt vkstsgnthl ggqdfdtnll 241 ehfkaefkkk tgldisddar alrrlrtaae rakrtlssvt qttvevdslf dgedfesslt 301 rARFEDLNAA LFKSTLEPVE QVLKdakisk SQIDEVVLVG GSTRipkvqk LLSDFFDGKq 361 leksinpdea vaygaavqga iltgqstsde tkdlllldva plslgvgmqg difgivvprn 421 ttvptikrrt fttvsdngtt vqfpvygger vnckENTLLG EFDLKnipmm pagepvleai 481 fevdangilk vtavekstgk SSNITISNAV GRIsseeiek MVNQAEEFKA ADEAFAKKHE 541 ARqrlesyva sieqtvtdpv lssklkrgsk skieaalsda laalqiedps adelrkaevg 601 lkrvvtkams sr
}

Figure 3. Location of tryptic peptides from the 66-kDa calmodulin-binding protein identified in yeast Ssb1/Hsp75 and Ssb2/ Hsp76 sequences. Matches of masses of tryptic peptides identified by MALDI-MS with predicted tryptic peptide masses in Ssb1/Hsp75 (Swiss-Prot accession number P11484) and Ssb2/ Hsp76 (Swiss-Prot accession number P40150) sequences are presented in bold. Twenty-one of 38 monoisotopic peptide masses were matched within a \pm 0.5 -Da error to predicted tryptic peptides expected from Ssb1/Hsp75, covering $37 \%$ of its sequence, and 19 of 38 peptide masses were matched to Ssb2/Hsp75, within the same error, covering $32 \%$ of its sequence. 
protein interactions that occur after heat shock or related stress (20). Ssb1/Hsp75 is a core component of the translating ribosome that interacts with both the nascent polypeptide chain and the ribosome, working as a chaperone by preventing the misfolding of newly synthesized proteins (21). The chaperone activity of Ssb1 has been involved in efficient protein turnover and its overexpression has been reported to suppress the growth defect caused by proteasome mutations (22).

\section{Putative calmodulin-binding sequence of Ssb1/Hsp75}

In order to identify the region of Ssb1/ Hsp75 responsible for calmodulin binding, the primary sequence of this protein was scanned for putative amphipathic $\alpha$-helices using the helical wheel program of the Antheprot V3.5B software (23) with a window of 18 . This analysis identified a single potential amphipathic $\alpha$-helix (residues 260 to 277) inside the N-terminal ATPase domain of Ssb1/Hsp75 (Figure 4). Inspection of this region using the Chou-Fasman algorithm (24) of Antheprot indeed predicted an $\alpha$-helix conformation for this sequence (results not shown). We found that the putative calmodulin-binding domain of Ssb1/Hsp75 shares $89 \%$ similarity to the experimentally determined calmodulin-binding domain (resi-

Figure 4. Primary amino acid sequence and helical wheel diagram of the putative calmodulinbinding domain from Ssb1/ Hsp75. The helical diagram of the putative calmodulin-binding domain (residues 260 to 277) from Ssb1/Hsp75 (Swiss-Prot accession number P11484) was generated by the helical wheel program of the Antheprot software (23). Residues within shaded circles are hydrophobic whereas those within non-shaded circles are hydrophilic. Hydrophilic amino acids with side chains having basic characteristic are marked with $a+$ sign.

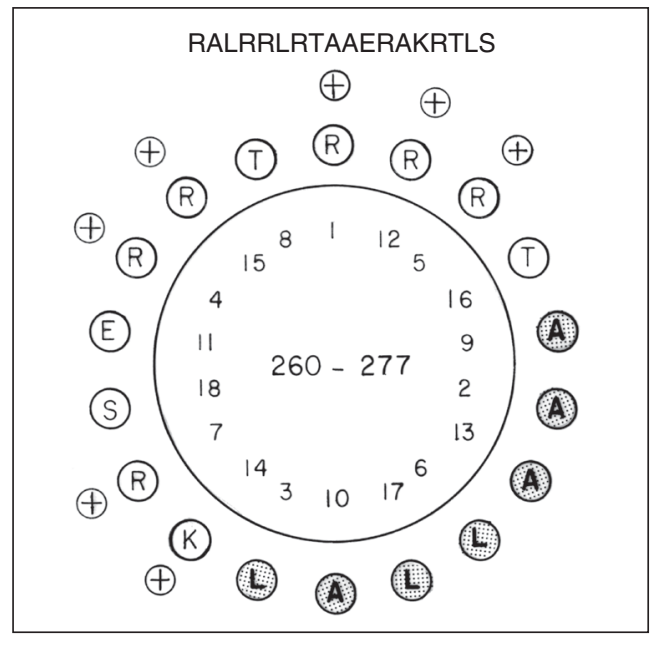

dues 257 to 277) from mouse Hsp70 (25), which does not conform to any of the three classes of calmodulin-binding motifs described previously (4) and has been classified as a divergent calmodulin-binding motif restricted to this protein. The alignment of the calmodulin-binding sequence from mouse Hsp70 (Swiss-Prot accession number P17879) with the sequences of 113 members of the HSP70 family (recovered from the Swiss-Prot database) using Clustal W (26) showed that it is conserved in near half of them (Figure 5), indicating that regulation of Hsp70 activity by calmodulin could be a recurrent theme among different organisms. In fact, 5 isoforms of Hsp70 from Arabidopsis thaliana have been found to bind calmodulin in a screening of expression libraries with a mixture of radiolabeled calmodulin isoforms (27).

\section{Discussion}

Eukaryotic cells respond to environmental stresses through a variety of signal transduction mechanisms, including activation of a $\mathrm{Ca}^{2+}$-dependent signaling pathway. Hypotonic (28) or hypertonic (29) shock can induce a transient increase in cytosolic $\mathrm{Ca}^{2+}$ concentration in yeast cells. Differently from mammalian cells, where the primary $\mathrm{Ca}^{2+}$ stores are the endoplasmic or sarcoplasmic reticulum, the calcium influx in S. cerevisiae comes from the vacuole and a protein homologue of transient receptor potential channels - known as Yvclp - is required for this release (29). The heat resistance of mammalian cells is a $\mathrm{Ca}^{2+}$ dependent process that can be affected by calcium chelators, calcium ionophores and anticalmodulin compounds (30), and by overexpression of $\mathrm{Ca}^{2+}$-binding protein (31). Furthermore, in these cells, some heat shock proteins, as Hsp70 and Hsp90, are calmodulinbinding proteins $(25,32)$.

In the present study, we identified Ssb1/ Hsp75, a member of the HSP70 family from $S$. cerevisiae, as a calmodulin-binding protein based on its ability to complex to calmodulin- 
agarose in the presence of $\mathrm{Ca}^{2+}$. A putative calmodulin-binding sequence was identified inside the N-terminal ATPase domain of Ssb1/ Hsp75 (residues 260 to 277) based on its predicted propensity to form an amphipathic $\alpha$-helix. It is interesting to note that this sequence displays $89 \%$ similarity to the experimentally determined calmodulin-binding domain from mouse Hsp70 (residues 257 to 277) (25) and was found to be conserved in near half of 113 Hsp70 sequences investigated from yeast to plants and animals (Figure 5). This relatively low number of Hsp70 sequences possessing the conserved calmodulin-binding motif may be attributed to the very stringent criterion that was used to include a sequence in this functional class. The non-conservative change of only one amino acid was sufficient to exclude a candidate protein since the exchange of a hydrophobic with a hydrophilic amino acid (or vice versa) could disrupt the amphipathic nature of the helix and prevent the binding of calmodulin.

A representative dendrogram constructed from a subset of sequences spanning the calmodulin-binding domain pinpointed among all Hsp70s (in order to avoid crowding in the final plot) is shown in Figure 6. This dendrogram shows the members of Hsp70 family grouped in three distinct branches (labeled $\mathrm{A}, \mathrm{B}$, and $\mathrm{C}$ in Figure 6). Two such branches (A and C) solely consist of non-calmodulinbinding Hsp70 corresponding to the subfamilies of BIP/GR78 proteins localized in the lumen of the endoplasmic reticulum, and of DnaK proteins of prokaryotes, respectively, which are not expected to be accessible to calmodulin. On the other hand, branch B forms a heterogeneous group of eukaryotic cytosolic Hsp70s composed of putative calmodulin-interacting proteins (all Hsp70 listed in Figure 5) together with other eukaryotic cytosolic proteins whose sequences do not conform to the conserved calmodulin-binding motif.

This last observation raises the question of whether the criterion used to include an $\mathrm{Hsp} 70$

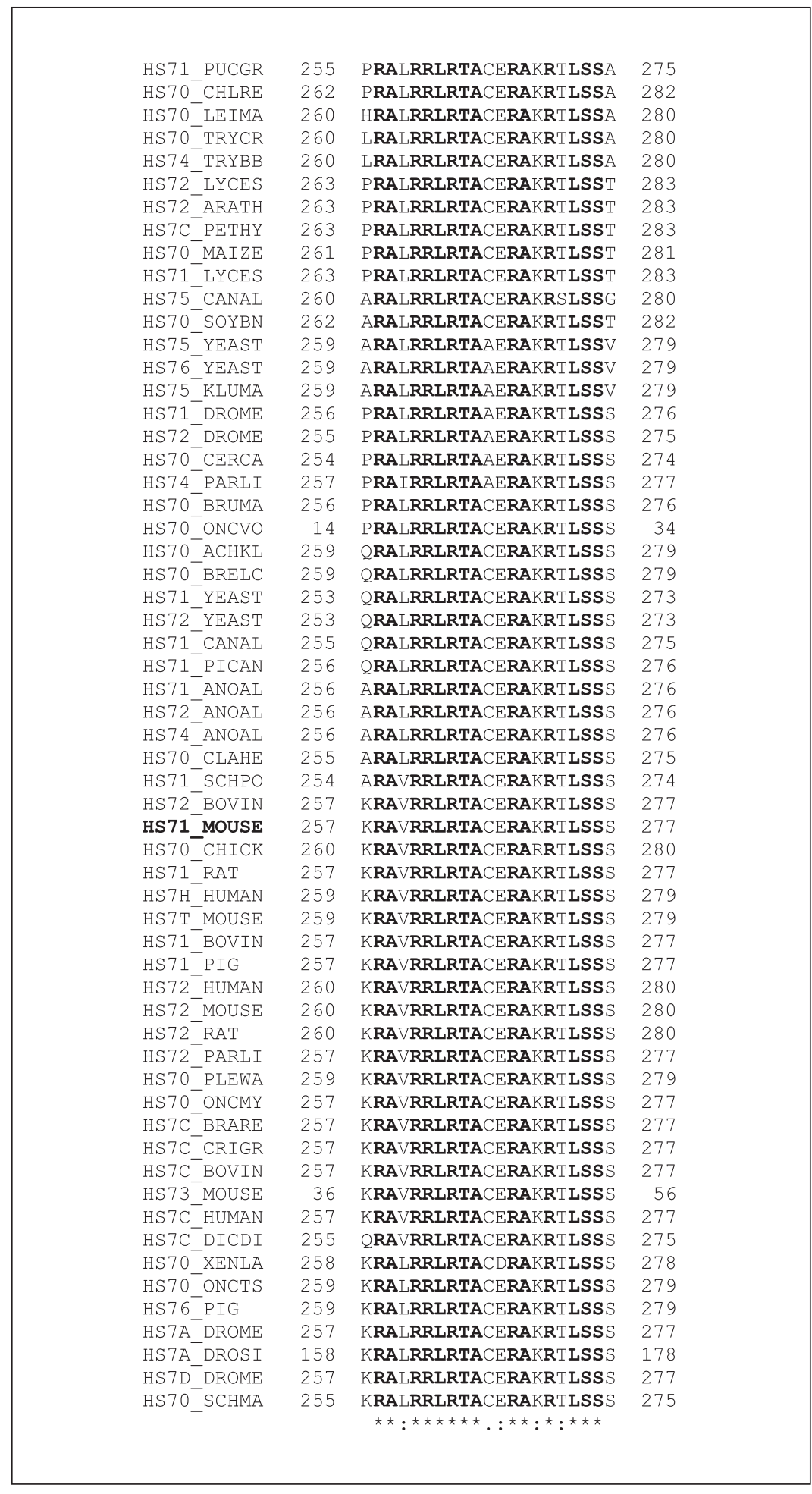

Figure 5. Alignment of the amino acid sequence of the experimentally determined calmodulin-binding peptide from the mouse Hsc70 (bold) with other members of the HSP70 family, including Hsp75 from Saccharomyces cerevisiae. The sequences were aligned using the Clustal W program. 


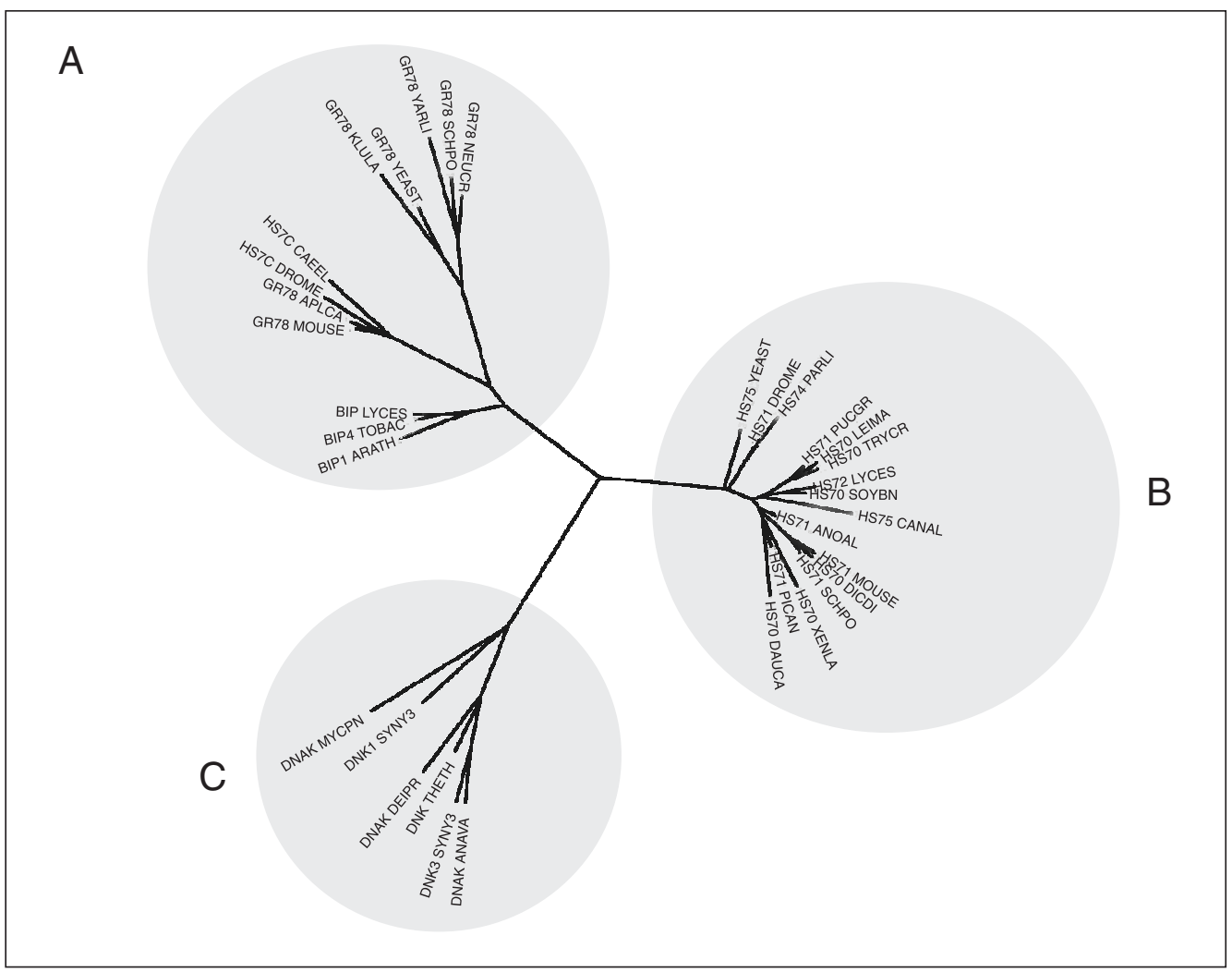

Figure 6. Dendrogram from the alignment of a subset of calmodulin-binding regions pinpointed among all Hsp70s generated by Clustal W. Members of the Hsp70 family were grouped into three distinct branches (labeled A, B, and $C$ ). Branches $A$ and $C$ comprise the non-calmodulin-binding BIP/GR78 proteins localized in the lumen of the endoplasmic reticulum and by DnaK proteins of prokaryotes, respectively. Branch B forms a heterogeneous group of eukaryotic cytosolic Hsp70s composed of putative calmodulin-interacting proteins together with other eukaryotic cytosolic proteins whose sequences do not conform to the conserved calmodulin-binding motif. A reduced set of sequences was used in order to avoid crowding in the final plot but the general appearance of the dendrogram does not change if all sequences are included in alignment.

member in the class of calmodulin-binding proteins should be so stringent, excluding a functional domain despite its slight divergence from the deduced motif. Conversely, our arbitrary division could have a real physiological significance and, in fact, eukaryotic cytosolic Hsp70 could exist in two types: regulated or non-regulated by calmodulin.

It is surprising that the well-characterized calmodulin-binding motif of mouse Hsp70 (25) was long considered not to be functional in any other member of the numerous HSP70 family, except for a maize Hsp70 (33). This was probably due to the fact that this motif was originally considered to be a divergent one, different from known "classical" calmodulin-binding motifs, and restricted only to mouse Hsp70. In the present study, we have assigned the potential calmodulin-binding activity of Hsp70 to more than half of the known members of this family, from yeast to plant and animal cells, opening the possibility to analyze the new evolutionarily conserved role of calmodulin in such key processes as protein biosynthesis and folding as well as in the quality control of biosynthesis. Furthermore, the present study incorporates members of the HSP70 family as important co-players of the $\mathrm{Ca}^{2+}$ signaling pathway.

These considerations lead us to predict that calmodulin and Bag-1 compete for binding to the same region of Hsp70, where the binding of calmodulin would block the ADPATP exchange cycles of this protein. Indeed, it has been reported that the binding of calmodulin to maize Hsp70 inhibited the ATPase activity of this protein (33). However, the effect of the displacement of Bag-1 by calmodulin on the Hsp70 activity could not be anticipated, since in mammalian cells Bag-1 isoforms differentially affect the chaperone property of Hsp70.

Among the Hsp70s having a calmodulinbinding sequence is bovine Hsc70 (SwissProt accession number Q27965), a structur- 


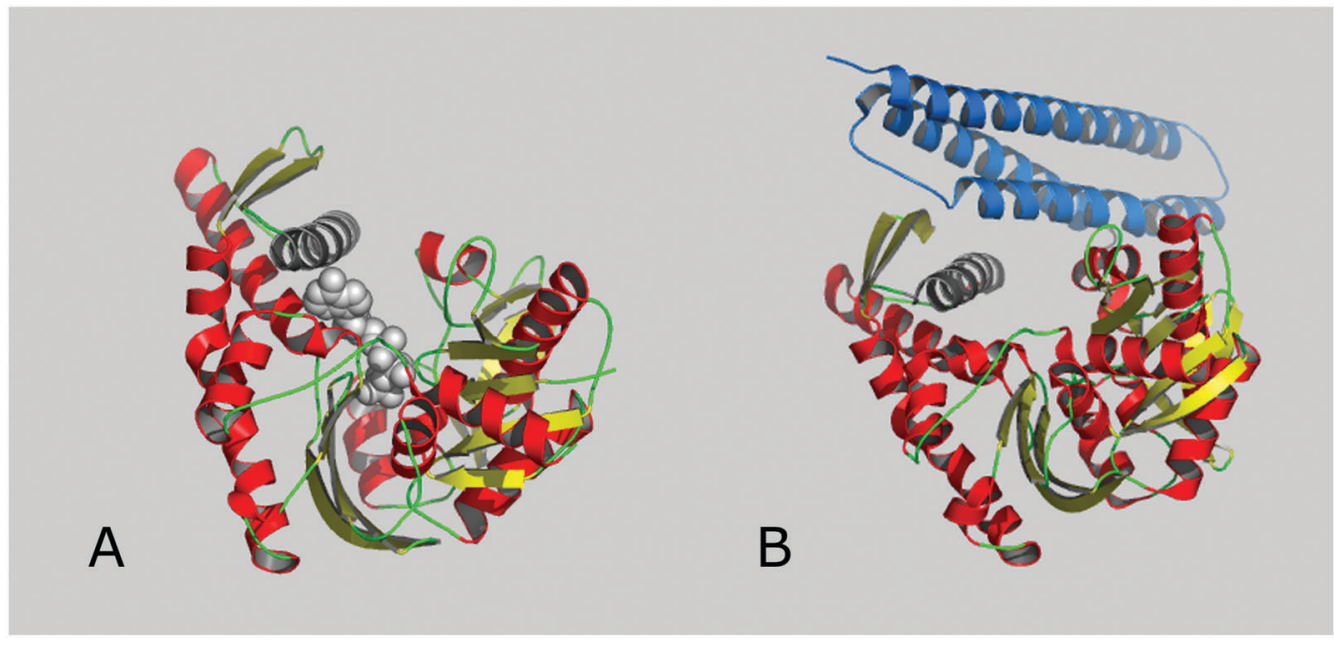

ally well-characterized protein whose N-terminal 44-kDa ATPase domain crystal structure has been solved at a resolution of $2.3 \AA$ (PDB identifier 1NGJ) (34). The conserved calmodulin-binding domain of bovine $\mathrm{Hsc} 70$ lies on an $\alpha$-helix (residues 257-274) at the border of its ATP-binding pocket (Figure 7A), which is also the target site for Bag-1 binding (35) (Figure 7B).

The chaperone activity of Hsp70 involves cycles of peptide binding and release, which are coupled to ATP binding, hydrolysis and nucleotide exchange. Efficient substrate release then requires the exchange of ADP for ATP mediated by Bag-1. Upon interaction with the ADP-bound state of Hsp70, Bag-1 promotes ADP release by opening the nucleotide-binding cleft of Hsp70. Since there is an excess of ATP over ADP and Bag proteins in the eukaryotic cytosol, ATP enters the nucleotide-binding pocket and displaces bound Bag1 , resulting in an acceleration of nucleotide exchange rate (36).

The structure of the complex between Bag-1 and bovine Hsc70 has been solved at a resolution of $1.9 \AA$ (PDB identifier 1HX1) (37). Interaction between Bag-1 and Hsc70 is stabilized by electrostatic interactions, mainly exploiting residues $\mathrm{Glu}^{212}, \mathrm{Asp}^{222}$, $\mathrm{Arg}^{237}$, and $\mathrm{Gln}^{245}$ in Bag-1. Interestingly, $\mathrm{Glu}^{212}$ and $\mathrm{Asp}^{222}$ interact with $\mathrm{Arg}^{261}$ and $\mathrm{Arg}^{262}$, two residues located inside the puta- tive calmodulin-binding sequence of $\mathrm{Hsc} 70$.

These observations lead us to predict that calmodulin and Bag-1 could compete for binding to the same region of Hsp70, where the binding of calmodulin would block the ADP-ATP exchange cycles of this protein. However, the effect of the displacement of Bag-1 by calmodulin on Hsp70 activity could not be anticipated, since in mammalian cells Bag-1 isoforms differentially affect the chaperone property of Hsp70.

A unique yeast protein containing a Bag-1 domain (InterPro accession number IPR003103) was identified by robotics server analysis at InterPro (www.ebi.ac.uk/interpro) and it was experimentally confirmed that the Bag domain of Sln1 (SwissProt accession number P40548) can specifically bind to Ssa and Ssb cytosolic forms of Hsp70 and that this interaction modulates the nucleotide exchange activity of this chaperone (38).

In addition to interacting with Ssb1/ Hsp75, the $\mathrm{Ca}^{2+} /$ calmodulin complex has also been reported to interact with the ribosomal protein L19 (39), the elongation factors EF-1 $\alpha$ (40) and Dst1p (7), all proteins involved in the translation machinery. Thus, it appears that $\mathrm{Ca}^{2+} /$ calmodulin regulates several steps of protein biosynthesis in a concerted way, although the role of calmodulin in the translational process requires further clarification.
Figure 7. $A$, Crystal structure of the $\mathrm{N}$-terminal ATPase domain of bovine Hsc70 (SwissProt accession number Q27965, PDB entry $1 \mathrm{NGl})$. $B$, Crystal structure of the $\mathrm{N}$-terminal ATPase domain of bovine Hsc70 in complex with a Bag-1 domain of a human protein (PDB identifier $1 \mathrm{HX} 1$ ). In both cases the putative calmodulin-binding domain situated within an $\alpha$-helix located in the ATP-binding pocket of bovine Hsc70 (residues 257274 ) is shown in black and the ATP molecule in white. 


\section{References}

1. Kraus PR, Heitman J. Coping with stress: calmodulin and calcineurin in model and pathogenic fungi. Biochem Biophys Res Commun 2003; 311: 1151-1157.

2. Chin D, Means AR. Calmodulin: a prototypical calcium sensor. Trends Cell Biol 2000; 10: 322-328.

3. O'Neil KT, DeGrado WF. How calmodulin binds its targets: sequence independent recognition of amphiphilic alpha-helices. Trends Biochem Sci 1990; 15: 59-64.

4. Rhoads AR, Friedberg F. Sequence motifs for calmodulin recognition. FASEB J 1997; 11: 331-340.

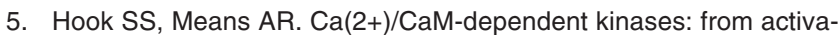
tion to function. Annu Rev Pharmacol Toxicol 2001; 41: 471-505.

6. Cyert MS, Kunisawa R, Kaim D, Thorner J. Yeast has homologs (CNA1 and CNA2 gene products) of mammalian calcineurin, a calmodulin-regulated phosphoprotein phosphatase. Proc Natl Acad Sci U S A 1991; 88: 7376-7380.

7. Stirling DA, Welch KA, Stark MJ. Interaction with calmodulin is required for the function of Spc110p, an essential component of the yeast spindle pole body. EMBO J 1994; 13: 4329-4342.

8. Bohl F, Kruse C, Frank A, Ferring D, Jansen RP. She2p, a novel RNA-binding protein tethers ASH1 mRNA to the Myo4p myosin motor via She3p. EMBO J 2000; 19: 5514-5524.

9. Winter DC, Choe EY, Li R. Genetic dissection of the budding yeast Arp2/3 complex: a comparison of the in vivo and structural roles of individual subunits. Proc Natl Acad Sci U S A 1999; 96: 7288-7293.

10. Zhu H, Bilgin M, Bangham R, Hall D, Casamayor A, Bertone P, et al. Global analysis of protein activities using proteome chips. Science 2001; 293: 2101-2105.

11. Ho Y, Gruhler A, Heilbut A, Bader GD, Moore L, Adams SL, et al. Systematic identification of protein complexes in Saccharomyces cerevisiae by mass spectrometry. Nature 2002; 415: 180-183.

12. Hazbun TR, Malmstrom L, Anderson S, Graczyk BJ, Fox B, Riffle M, et al. Assigning function to yeast proteins by integration of technologies. Mol Cell 2003; 12: 1353-1365.

13. Smith PK, Krohn RI, Hermanson GT, Mallia AK, Gartner FH, Provenzano MD, et al. Measurement of protein using bicinchoninic acid. Anal Biochem 1985; 150: 76-85.

14. Laemmli UK. Cleavage of structural proteins during the assembly of the head of bacteriophage T4. Nature 1970; 227: 680-685.

15. dos Santos CF, Larson RE, Panek AD, Paschoalin VM. $\mathrm{Ca}^{2+} / \mathrm{cal}-$ modulin-binding proteins in yeast. Catabolite repression and induction by carbon sources. Biochem Mol Biol Int 1997; 41: 359-366.

16. Zhang W, Chait BT. ProFound: an expert system for protein identification using mass spectrometric peptide mapping information. Anal Chem 2000; 72: 2482-2489.

17. Boorstein WR, Ziegelhoffer T, Craig EA. Molecular evolution of the HSP70 multigene family. J Mol Evol 1994; 38: 1-17.

18. Chappell TG, Welch WJ, Schlossman DM, Palter KB, Schlesinge MJ, Rothman JE. Uncoating ATPase is a member of the 70 kilodalton family of stress proteins. Cell 1986; 45: 3-13.

19. Chirico WJ, Waters MG, Blobel G. $70 \mathrm{~K}$ heat shock related proteins stimulate protein translocation into microsomes. Nature 1988; 332: 805-810.

20. Lewis MJ, Pelham HR. Involvement of ATP in the nuclear and nucleolar functions of the $70 \mathrm{kd}$ heat shock protein. EMBO J 1985; 4 : 3137-3143.

21. Pfund C, Lopez-Hoyo N, Ziegelhoffer T, Schilke BA, Lopez-Buesa $\mathrm{P}$, Walter WA, et al. The molecular chaperone Ssb from Saccharomyces cerevisiae is a component of the ribosome-nascent chain complex. EMBO J 1998; 17: 3981-3989.

22. Ohba M. Modulation of intracellular protein degradation by SSB1-
SIS1 chaperon system in yeast S. cerevisiae. FEBS Lett 1997; 409: 307-311.

23. Deleage G, Clerc FF, Roux B, Gautheron DC. ANTHEPROT: a package for protein sequence analysis using a microcomputer. Comput Appl Biosci 1988; 4: 351-356

24. Chou PY, Fasman GD. Prediction of the secondary structure of proteins from their amino acid sequence. Adv Enzymol Relat Areas Mol Biol 1978; 47: 145-148.

25. Stevenson MA, Calderwood SK. Members of the 70-kilodalton heat shock protein family contain a highly conserved calmodulin-binding domain. Mol Cell Biol 1990; 10: 1234-1238.

26. Thompson JD, Higgins DG, Gibson TJ. Clustal W: improving the sensitivity of progressive multiple sequence alignment through sequence weighting, position-specific gap penalties and weight matrix choice. Nucleic Acids Res 1994; 22: 4673-4680.

27. Reddy VS, Ali GS, Reddy AS. Genes encoding calmodulin-binding proteins in the Arabidopsis genome. J Biol Chem 2002; 277: 98409852.

28. Batiza AF, Schulz T, Masson PH. Yeast respond to hypotonic shock with a calcium pulse. J Biol Chem 1996; 271: 23357-23362.

29. Denis V, Cyert MS. Internal $\mathrm{Ca}(2+)$ release in yeast is triggered by hypertonic shock and mediated by a TRP channel homologue. $J$ Cell Biol 2002; 156: 29-34.

30. Landry J, Crete P, Lamarche S, Chretien P. Activation of $\mathrm{Ca}^{2+}$ dependent processes during heat shock: role in cell thermoresistance. Radiat Res 1988; 113: 426-436.

31. Evans DP, Simonette RA, Rasmussen CD, Means AR, Tomasovic $\mathrm{SP}$. Altered synthesis of the $26-\mathrm{kDa}$ heat stress protein family and thermotolerance in cell lines with elevated levels of calcium-binding proteins. J Cell Physiol 1990; 142: 615-627.

32. Minami Y, Kawasaki H, Suzuki K, Yahara I. The calmodulin-binding domain of the mouse $90-\mathrm{kDa}$ heat shock protein. J Biol Chem 1993 268: 9604-9610.

33. Sun XT, Li B, Zhou GM, Tang WQ, Bai J, Sun DY, et al. Binding of the maize cytosolic Hsp70 to calmodulin, and identification of calmodulin-binding site in Hsp70. Plant Cell Physiol 2000; 41: 804-810.

34. Johnson ER, McKay DB. Mapping the role of active site residues for transducing an ATP-induced conformational change in the bovine 70-kDa heat shock cognate protein. Biochemistry 1999; 38: 1082310830.

35. Takayama S, Xie Z, Reed JC. An evolutionarily conserved family of Hsp70/Hsc70 molecular chaperone regulators. J Biol Chem 1999; 274: 781-786.

36. Gassler CS, Wiederkehr T, Brehmer D, Bukau B, Mayer MP. Bag$1 \mathrm{M}$ accelerates nucleotide release for human $\mathrm{Hsc70}$ and $\mathrm{Hsp} 70$ and can act concentration-dependent as positive and negative cofactor. J Biol Chem 2001; 276: 32538-32544.

37. Sondermann H, Scheufler C, Schneider C, Hohfeld J, Hartl FU, Moarefi I. Structure of a Bag/Hsc70 complex: convergent functional evolution of Hsp70 nucleotide exchange factors. Science 2001; 291 : 1553-1557.

38. Sondermann H, Ho AK, Listenberger LL, Siegers K, Moarefi I, Wente SR, et al. Prediction of novel Bag-1 homologs based on structure/ function analysis identifies Snl1p as an Hsp70 co-chaperone in Saccharomyces cerevisiae. J Biol Chem 2002; 277: 33220-33227.

39. Sonnemann J, Bauerle A, Winckler T, Mutzel R. A ribosomal calmodulin-binding protein from Dictyostelium. J Biol Chem 1991; 266: 23091-23096

40. Kaur KJ, Ruben L. Protein translation elongation factor-1 alpha from Trypanosoma brucei binds calmodulin. J Biol Chem 1994; 269: 23045-23050. 